\title{
The development of the nursing profession in a globalised context: a qualitative case study in Kerala, India
}

\section{$\underline{\text { Abstract }}$}

In the paper, we are looking at the relationship between globalisation and the professional project, using nursing in Kerala as an exemplar. Our focus is on the intersection of the professional project, gender and globalisation processes. Included in our analysis are the ways in which gender affects the professional project in the global south, and the development of a professional project which it is closely tied to global markets and global migration, revealing the political-economic, historical, and cultural factors that influence the shape and consequences of nurse migration

The phenomenon that enabled our analysis, by showing these forces at work in a particular time and place, was an outbreak of strikes by nurses working in private hospitals in Kerala in 2011-2012.

Keywords: nursing; Kerala; sociology; sociology of professions; employment; globalisation

\section{Background}

Research in the sociology of the healthcare professions has tended to be conducted in a single nation state or as comparisons between two or more nation states (Abbott 1988). However, globalisation is acknowledged to be an issue of central importance in contemporary sociology. Though there are numerous competing definitions of globalisation, in this paper we align ourselves with Robertson (1992) "both to the compression of the world and the intensification of consciousness of the world as a whole...." (p8). In terms of timescale, for the purposes of this paper, we are largely focussing on the 'third wave' of globalisation, since 1989. This third wave is characterised by its total global reach, mediated by advanced technology, with unprecedented levels of global migration. Dingwall (1999) argues that a globalised world will need globalised professions, not least as trust-building organisations in an increasingly complex world, with limited face-to-face contact.

In this paper we consider the relationship between globalisation and the professional project of one profession, nursing, in one Indian State (Kerala). As we argue below, nursing in Kerala is particularly strongly exposed to global processes. 
There was a general re-alignment of sociological thinking on professions in the 1970s. Hitherto, analysis of the professions had been influenced by functionalist approaches, with its main emphasis on defining what a profession was, and delineating its social features. The (neo-Weberian) work of authors such as Larson (1977) and Abbott (1988) was part of a wider trend towards a more critical stance on the professions. Larson (1977) introduces the idea of the 'professional project'. Rather than being altruistic social institutions, professions are viewed as pursuing their own interests. For Larson, the professional project includes programmatic efforts to secure professional status and social respectability, and to control jurisdiction of work, access to training, accreditation and, ultimately, to labour markets. In addition, the profession develops an ideology that justifies these privileges by appeal to professional skill and wider social benefit. Larson (1977) argues that the main focus of these efforts is the state, which is the principal agent in the creation and control of professions.

Abbott (1988) points to the importance of other, competing occupational groups in the professionalisation process. For Abbott, professionalisation is an attempt by a group of workers to define a 'jurisdiction' over which they have a monopoly of knowledge, and can thus exercise control. This is only achieved through a process of struggle with other groups of workers: "The history of jurisdictional disputes that is the real, the determining history of the professions" (p2). One of Abbott's major contributions is that he shows how professionalisation is a dynamic process. Professional status needs to be defended, as well as achieved. Though Abbott is critical of Larson, claiming that her work places too much emphasis on the state, and pays insufficient attention to struggle with other professions, we believe these approaches can be fruitfully combined to analyse the professional project in a context where both state and competing professions are significant. An issue of importance, in a strongly gendered profession like nursing, is the comparative neglect of gender as an issue in these professionalisation theories, especially in terms of professional status (Witz 1992). Equally, a limitation of most writers in this field is that the analysis draws principally on the history of the professions in the developed world.

Comprising the majority of healthcare workers worldwide, nursing is extensively integrated into contemporary processes of globalisation. The largest group of health care professionals who are working outside their country of origin or training are nurses, due in no small part to the worldwide shortage of nurses, across all health care systems (Yeates 2009). As such, the professional project of nursing presents a significant and interesting case for analysis. 
The professionalization of nursing has been ongoing since its emergence as a profession in the nineteenth century. However, the pursuit of nursing's professional project has always been problematic due to the overwhelming influence of the medical profession. This has caused nursing's status as a profession to be questioned by inter alia Etzioni (1969) who characterised nursing (along with social work and teaching) as a semi-profession. For a subordinate profession like nursing, the professional project will necessarily take the form of a dual closure strategy (Witz 1992). This entails an attempt to usurp the more powerful profession of medicine (by, for instance, taking on new roles which have hitherto been the province of doctors), while at the same time closing off nursing and its work to rivals of lower status. As we shall see, there is evidence of similar conflicts in our case study.

Gender has been shown to have a significant relationship with professional projects (Witz 1992), with professions which are predominately female finding it harder to pursue a professional project than more male-dominated professions. This is due to gendered notions about what is appropriate behaviour for women in the workplace, women's careers and the status of work done largely by women (Witz 1992). The status of nursing as a strongly feminized profession has particular consequences for its professional project. Davies (1995) shows how defining nursing as women's work devalues its importance and silences nurses in policy debates - while, at the same time, nurses are individually lauded for their work. Both historical and contemporary studies show how problematic this gendered status is for nursing as a profession. Reverby's (1987a,b) historical analysis of professionalisation by nursing in the USA makes clear the importance of gendered notions of, for instance, 'duty' in framing nursing's professional project. She shows how the tension between 'order' and 'caring' in the history of nursing in the USA, as well as a struggle between nursing elites and the 'rank and file' explain nursing's failure to achieve the professional status of other groups (1987a,b). Rankin (2009), focused on Canada, analyses the contemporary attack on nursing's professional project by New Public Management. However, these analyses of gender and professional projects have been conducted in the global North. The ways in which gender affects the professional project in the global South has been explored indirectly by Nair (2010) who analysed the relationship between gender and collective bargaining by striking nurses, and George (2015) whose study of nurses' migration from Kerala to the USA shows the intersection of both race and gender with the migrant nurses' professional status. As we will show, globalisation can intersect with gender in ways that has perhaps surprising consequences for the professional project. 
The literature on globalisation and nursing in the global South takes as its principal concern migration (Kingma 2006). As such, the main focus of this literature is the motivations and drivers of migration ('push' and 'pull' factors), principally economic and social (Prescott and Nichter 2014). Because of its long-standing and substantial contribution to the migration of nurses, the Philippines has been the subject of several studies (Ronquillo et al 2011, Lorenzo et al 2007, Brush 2010, Masselink \& Lee 2010). Though the main focus of this body of work is on the causes and consequences of globalisation for nursing in the Philippines, several points of contact with what might be termed a professional project can be discerned. The first of these is a strongly globalised nursing curriculum (Ortiga 2014). Curricula for nursing developed in the 1970s in the Philippines and were strongly influenced by the explicit policy of the Philippine state to produce nurses for export (Percot and Irudaya Rajan 2007), part of a wider response by the Philippine state to globalisation (Yeates 2009). Second, a consequence of migration has been the development of a two-tier profession in exporting countries like the Philippines. Nurses who move abroad have high status and remuneration, whereas as those who stay at home often endure low wages and status, as well as poor working conditions (Ronquillo et al 2011, Brush 2010). Hence, in the Philippines, high levels of migration are thought to have caused a somewhat laissez-faire policy in terms of state regulation, as policy-makers assume that most nurses will leave the Philippines to work abroad.

Kerala, a state in South India, is also a particularly salient case for the analysis of globalisation processes, in that large numbers of nurses from Kerala have migrated to work both in the Gulf and the global North (Nair 2012). The antecedents of migration for Kerala nurses include the historical legacy of the British Empire and longstanding trading links between Kerala and the Gulf. During colonial times, British missionaries attempted to redefine and professionalise nursing as a 'respectable' vocational career. British mission hospitals established Nursing Schools and recruited poor women or widows from predominantly Christian communities. Kerala nurses remain substantially Christian (Percot and Irudaya Rajan 2007). Nurse migration from Kerala began during the 1960s, often facilitated by missionary networks but was not an organised movement. Missionary nursing schools appointed Kerala nurses to senior positions, due to their faith, or English language skills. Also important in the development of nursing as a profession in India was the military, who also employed Kerala nurses preferentially (Nair 2012). 
The migration of nurses is clearly a gendered phenomenon, part of a global 'care chain' (Hochschild 2000, Walton-Roberts 2012, Thomas 2008), though women's migration remains neglected analytically. Connell (2010) considers the impact of migration on countries within the global South, and analyses policy responses to migration by health systems in these countries, though without taking an explicit 'sociology of professions' standpoint. Iredale's (2005) paper analyses how the recruitment of migrant professionals in the Global North is a strongly gendered process, but does not focus on the impact of migration on the status of professions in countries like India that supply migrants.

The experience of migration for nurses in India has been studied by Percot and Rajan (2007) and Nair (2012) who show how a well-established route from Kerala, via the Indian metropolises, to the Gulf and sometimes beyond to the Global North, has developed in the last 25 years. For women from Kerala, migration as nurses represents not just a financial and career opportunity, but a job that can enhance their marriage prospects, and pay for a dowry or education for themselves and other family members. Migration by Kerala nurses is typically a family project (Nair and Percot 2007) where several members may migrate, financed by other members.

For women, migration can also bring a greater degree of personal freedom (Percot 2006). George $(2015,2000)$ studied the gendered experience of Kerala nurses in the USA, where the nurses had been the primary migrant, who then sponsored their husbands. Adhikari (2013) has studied Nepali nurses moving to the UK, and the impact migration has on their wider status, with particular reference to gender. These studies show that for women, migration can often lead to poor working conditions, discrimination and even violence, while (simultaneously and paradoxically) also affording better pay, enhanced career opportunities and greater personal freedom. Kodoth and Kuriakose (2013) show that despite high and sustained levels of migration, national labour markets for Kerala nurses (in Europe) are heterogeneous, and volatile. The possibility of migration can disappear almost overnight by changes in national policy, such as the introduction of new language tests. Migrants are often forced to return to their country of origin. It has been suggested that these, and other reasons for return, mean that countries like India experience a 'brain circulation' rather than a 'brain drain'. Nursing and its professional project in Kerala might therefore benefit from the skills and experience of returners. Walton-Roberts and Rajan's (2013) study of (inter alia) returners suggests that many intended to migrate again, implying that there may not be long term benefit to nursing in Kerala. 
Education and educators have been central actors in professional projects in the global North. As Walton-Roberts $(2015,2010)$ has shown, the prospect of migration has had a large influence on nurse education in Kerala, including an expansion in the number of Schools of Nursing, mostly private. The majority of student nurses aspire to emigrate, and Faculty expect that they will. While there has not been an explicit state policy push towards producing nurses for export (as in the Philippines), the Indian state has not tried to prevent it, and has certainly connived at this policy (Walton-Roberts 2010). Though it has not been analysed hitherto in the literature, the consequences of mass migration for a professional project (certainly in a predominately female profession like nursing) have generally been assumed to be negative. However as we will show, the situation is not so simple.

\section{The Context of Nursing Work in India}

The development of nursing in India reflects the country's history and complex socio-cultural make up. Traditionally, amongst Hindu and Muslim communities, the need for female nurses to work outside of the home (including at night), to touch strangers, to mix with men, and to deal with bodily fluids (considered polluting within Hindu and Muslim cosmology) has meant that until relatively recently, nursing was a relatively stigmatised and low status profession (Abraham 1996, Somjee 1991). Johnson (2011) notes that the prospect of migration has led to a growth in the number of Hindu and Muslim women training as nurses, and in the number of men training. Hence, she argues that in a globalizing India, nursing is becoming a job "with prospects' transcending traditional caste, class and gender boundaries.

India's federal structure means that there are variations in nursing regulation in the constituent states, with State Nursing Councils (such as the Kerala Nurses and Midwives Council) having a major role, particularly in the regulation of education, at state level. Like the Philippines, nursing curricula in India are increasingly globalised (Yeates 2009). Research evidence on nurses' working conditions and job satisfaction in India is limited. However, reports indicate that nursing lacks clear career pathways and mechanisms for promotion; in-service training is rare (except in the best corporate hospitals); pay is low (especially in small private hospitals); and working conditions are often inadequate, lacking sufficient staff, equipment and infrastructure. One study in New Delhi found that nurse: patient ratios of 1:50 were normal. Nurses reported spending much of their time doing menial or unskilled work (Nair 2012). In a study of female health workers in Kolkata, more than $50 \%$ of respondents admitted experiencing sexual harassment at work (Chauduri 2007). Nurses in private hospitals in New Delhi staged a strike in 2010 in protest at low pay 
and exploitative working conditions (Nair 2010). Indeed, it was nursing strikes that were the impetus for our fieldwork, providing an opportunity to see debates about the status of nursing played out in public, as well as strikes by nurses being a comparatively rare phenomenon, globally. Organized strikes in private hospitals occurred in Kerala in 2011-2012, due to poor working conditions, low salary and repressive employment practices.

\section{Study Aim}

This study sought to examine how the development of a profession in a globalised context has an impact on the profession at home, beyond the usual concern about migration increasing staff shortages. We suggest that while the project of nursing in Kerala may follow broadly similar paths to those studied in the global North, the meanings ascribed to its actions and symbols will be different according to the cultural context. Also absent from existing analyses is consideration of the role of an extensive and lightly regulated private sector (as in India) in both health services and professional education. This potentially gives a very different shape to professionalising strategies and is a different context from those in which the original theories were developed. The study further sought to explore the impacts on a professional project when it is closely tied to global markets and migration, at a time when global context is changing rapidly, in line with Prescott and Nichter's (2014) call for more research on the "political-economic, historical, and cultural factors that pattern nurse migration and influence the complex effects of nurse migration" ( $\mathrm{p} 113)$.

\section{Methods}

The authors are a Kerala sociologist, a British nurse, and a British sociologist. One-to-one, semi-structured interviews were conducted in Kerala in March-June 2012 by the authors, sometimes working together, though several interviews were conducted by one author alone. Field sites were strike sites in front of hospitals in Kerala, which were at Ernakulam, Kothamangalam, Angamali and Thiruvananthapuram. We met officials of professional associations, training institutions, the Directorate of Medical Education, and the Kerala Nurses and Midwives Council (KNMC). Interviewees included striking nurses $(n=4)$; nurse activists/union representatives $(n=5)$; professional nursing association representatives $(n=3)$; nurse educators $(n=3)$. Interviews typically lasted an hour. The sample was selected purposively, drawing on the local author's networks, and we acknowledge that this is not fully representative of a large and diverse population. Interviewees were selected on the grounds that they had been involved in the strikes, or that they were influential in the professions 
(either in regulation or education) locally. Interviews were transcribed and analysed thematically, initially by one author, with analysis being checked and validated by the other authors. We also drew on newspaper coverage of the strikes, and on analysis of policy documents. Ethical approval was granted by the Centre for Women's' Development Studies, New Delhi.

\section{Results}

In this section, we will analyse the strikes and their causes, moving from the local and immediate context, to a more global view.

\section{Working Conditions and Status}

The incident that started the nursing strikes in Kerala was the suicide of a nurse (Indian Express 2012). A prevailing 'bond' system (see below) meant that she was trapped in a job where she could not hope to pay off her debts to her employer, nor move to another job. Her predicament resonated deeply with other nurses across the State, many of whom were finding themselves in a similar situation - as described by one of the leading strike organisers:

I am a nurse. I had taken bank loan of 3 Lakhs for my B.Sc. Nursing course. I am from a lower middleclass family which cannot spend money on the education of its children. Bank loan was the only way and we (family) took this loan because we thought we could pay back once I finish the course. As soon as I finished the course, I had to work under the bond and then I finished it and in order to get a job in another hospital, I had to be a trainee. Salary was Rs.1000, Rs.1500 and Rs. 2500. And, unlike, when I joined the course, when I finished the course, migration opportunities were not many. How am I going to pay back the money? Bank officials came to attach the house we were staying. We had mortgaged that for the loan. You know the social humiliation related to such a thing. My parents were shattered. That is all we had as an asset... for the whole family....... There is no way before us but to commit suicide. (Strike Organiser)

Strikes involved the private healthcare sector and were lengthy (up to 4 months), including sit-ins at the hospitals affected, and in some case, hunger strikes (for more detail on the strikes themselves see Nair et al, 2016). The proximal causes of the strikes were what might 
be expected in most labour disputes; wages and working conditions. Nurses in private sector health care in India typically have to agree to a 'bond' whereby they agree to work for a designated period of time for their employer, and their professional certificates of qualification are lodged with the employer to prevent them from changing jobs during this time. This puts the employers in a very strong position; nurses reported very low wages, long working hours, low levels of staffing and extensive 'deductions' from their salaries. Nurses who have trained at private sector schools of nursing are likely to be required to work for the hospital associated with the school of nursing for a period of time after qualification - again enforced by the bond system. In some cases, newly qualified nurses were required to work as unpaid 'interns' for a period of time after qualification. Employers justify the bond and internship systems by arguing that newly qualified nurses are often poorly trained, and, initially, are not able to undertake the work normally expected from a fully qualified nurse. In addition, the bond system is seen as a protection against excessive nurse turnover, whereby employers agree to provide training and internship opportunities in return for nurses staying at their institution for specified periods of time. The bond system is thus (partly) a response to migration by nurses in so far as it prevents nurses from leaving their training hospital, but one of the reasons nurses tolerate it, is that clinical experience is a pre-requisite for migration.

Other complaints related to lack of recognition and nursing skills being systematically undervalued. Nursing in India possibly suffers even more than nursing in the global North from being seen as gendered, low-status work (Davies 1995). This was exacerbated by employers requiring nurses to do tasks perceived as being menial.

There are many jobs that the nurses have to do in a hospital and not just the nursing jobs: menial, administrative and all sorts of work. For example, in XX hospital, Ernakulam, nurses have to sell frocks, dolls and so on in the maternity ward..... Unit helpers should do jobs like cleaning the beds and so on and nurses' job should be different. (Deputy Director of Nurse Education)

Though the professional title of nurse is legally protected in India, private sector employers regularly flout this law, employing underqualified and unqualified staff with the title of 'nurse'. A key activity for any professional group is to be able to police its boundaries, and prevent people who are not appropriately qualified from claiming that professional title. This appeared to be difficult for the nursing profession to enforce in the context of Kerala: 
A lot of workers who are working as nurses in private hospitals are not registered nurses, they're not fully qualified. (Official, Kerala Government Nurses' Association)

Evidently, working relationships with doctors were not always good, and professional boundaries contested. In India, this is exacerbated by the fact that many private hospitals are owned by doctors, thus making doctors, as employers, responsible for the poor wages and working conditions listed above.

What is evident is the management's role in keeping the status of the nurses' low. 75 $\%$ of the staff in a hospital is nurses. So it is beneficial to keep their salary low. Management, doctors and politicians act together to maintain the present situation and all these three have share in the major private hospitals in Kerala. (Senior Nurse, Public Sector)

Boundary disputes between nursing and medicine are also gendered in other parts of the world (Davies 1995, Allen 1997). In Kerala it appeared to be seen as 'inappropriate' for (female) nurses to strike, and doctors expected female nurses in particular to be submissive and obedient:

But doctors are always against them. Doctors want nurses to obey them unconditionally. They think that nurses' job is to obey doctors. Most hospitals have bond system and they keep the original certificates. You cannot take leave and the conditions of work are like that of slaves. It is against this we are fighting. We want to work and live like human beings. (Senior Figure in United Nurses Association)

Among them also there is some dispute. ... Especially female dominated we try to be more submissive. It is 'only' a 'ladies only' profession and that is one important reason for the exploitation. (Deputy Director, Nursing Education)

The Lure and Disappointments of a Global Nursing Market

We now turn to an analysis of the wider causes of the strikes, considering them in a wider context. Both the poor training standards and high turnover - justified by employers by the bond system - are phenomena linked to a globalised market for nurse education and employment. 
Migration, or the prospect of migration, had a pronounced effect on the aspirations, and reference points for nurses in Kerala. Many nurses working in private hospitals had trained as nurses with a view to migration, either to the Indian metropolises, the Gulf or (eventually) to the UK, USA, Australia or Canada (Nair 2012, Walton-Roberts 2015).

She had seen many those who attend her church becoming rich and climbing the social ladder by getting good employment in the Gulf and in the west, Germany, UK and the US. (Striking Nurse 2)

As mentioned previously, their employment locally in a private hospital was understood as a stepping stone to a more lucrative career, with much improved working conditions. The bond system made it hard for nurses to pursue these career aspirations. There are often several nurses in a family (Nair 2012, Percot and Irudaya Rajan 2007), and so many nurses had relatives working overseas, or in the large Indian cities, and thus they were well aware of how poor their own wages and working conditions were, by comparison, and were frustrated by the 'bond' system in their attempts to develop their careers. As well as the economic consequences, their inability to change jobs meant that they were trapped in debt and in low status work, affecting, in some cases, broader social phenomena, such as marriage prospects.

In fact as I told you I tried to go abroad as well. But now there are not many chances. In any case you need a few years' experience to go abroad but you need to start paying to the bank as soon as you finish the course. How is that possible when you get this small amount as your salary due to bond system or trainee system and so on. And there are not many opportunities unlike previous years for nurses. (Senior Figure in United Nurses Association)

\section{Male Nurses: Prospects and Protest within Nursing}

One of the consequences of the prospect of working abroad has been an influx of men into the traditionally female dominated nursing profession (Johnson 2011). This appears to have had an effect on the strikes, which were predominantly led by men, though the majority of the strikers were women. 
There are no more migration opportunities ... and men find it difficult in that situation. Life has become very difficult with bank loans and no opportunities to work abroad. These have caused these strikes. (Deputy Registrar KNMC)

But now with the recent increase in the number of boys, they come forward to talk about their dissatisfaction. (Treasurer, Nurses' Association)

Men were considered by some of our interviewees to be more militant, and to have a greater knowledge of how to organise and protest. New nursing unions were formed among the striking nurses, and their leadership was principally male (Biju 2013).

It is true that male nurses take the lead in most of the strikes. Girls are afraid to come forward ... they are afraid of many factors including their reputation. (Nursing Activist; male)

Additionally, there was a perception amongst the respondents that the local employment situation for men was even more precarious than for women as employers were reluctant to hire men, due to their perceived greater militancy:

Nowadays many boys have opted for nursing - that is a recent phenomenon, but finally what happened is that now the management is not willing to take boys... the doctors - the majority of them are males, but they do not like male counterpart in the nursing field ...they want to have more of ladies so that they can suppress them. Not only the doctors but other categories also - they want all the nurses to be ladies, but private sector management they are not taking the male candidates. they're asking them to go back - they don't want male candidates because they think that the whole issue has been created by the male students. (Senior Nursing Official, Directorate of Medical Education)

\section{Nursing Regulation}

In a still wider context, the strikes can be understood as a consequence of the economic liberalisation of India since the 1990s, a process strongly influenced by neo-liberal, globalising forces. The general policy of a diminution in regulation had meant that it was possible for private schools of nursing to be established - in Kerala, and the other southern states of India. These number in the hundreds, often charge extortionate fees, provide a 
highly variable standard of education and exist in a context where regulation is deemed to be weak and ineffective (Walton-Roberts 2015).

We have 18 schools of nursing in the government sector (in Kerala) and (now) nearly 220 schools in the private sector. [Referring to an unregulated expansion of private training institutions] Mushrooming of institutions is one major factor and Karnataka (around double the number of registration in Kerala's institutions) and Tamil Nadu provide very bad training. I have seen nursing students come and stand in one corner [in the ward] and go back. They have no hands-on experience (Official with the Kerala Nursing \& Midwifery Council)

The rapid growth of private sector nurse education (Walton-Roberts 2015), a response to globalisation, has been problematic for the state regulators of nursing in India, who have often been unable or unwilling to enforce educational standards in the private sector schools of nursing. Some interviewees were dubious about the quality of the training nursing students in private colleges received:

So the students aren't spending enough time in wards or clinics. They are not seeing enough patients or variety of patients to learn clinical skills. That is because the [private] colleges just want to recruit more and more students. (Nurse Educator, State Sector)

This was because of the expansion of private nursing schools. There was insufficient capacity in hospitals to absorb the large number of student nurses, and hospitals gave priority to their 'own' students. Hence the majority of the training that many students received was classroom-based. Corruption is a substantial issue (Bhaumik 2013). It is alleged that private schools of nursing can gain their accreditation through bribery of officials from the nursing regulators.

Malpractices exist among the supervisors. Corruption is rampant and other political and other pressures on the Indian Nursing Council. They are to introduce registration of [private] hospitals ... the government can [legally] But now government cannot enforce [regulation]. (Official, Kerala Government Nurses' Association)

The solution to this problem proposed by the Kerala Nursing and Midwifery Council (KNMC) was an effective 'closing of boundaries', that is, that the KNMC would not validate 
qualifications obtained in other Indian states, notably Karnataka and Andhra Pradesh. In addition, they suggested a cap on the number of private schools of nursing in Kerala, in order to maintain the State's 'international' reputation.

Outside Kerala, especially Karnataka and Tamil Nadu, Andhra [Pradesh] also - the quality is not that good. I think nursing is in a critical state. In Kerala we will soon have a qualifying examination. (Registrar KNMC)

This means that KNMC will set an examination for nurses, additional to the qualification they have gained from their College, with the aim of driving up standards, and, indirectly, enhancing the professional project of nursing, as well as the employability of Kerala nurses in the global labour market. The KNMC was also seeking to raise the academic entry requirements for nursing, though these initiatives have been opposed by the INC.

As discussed above, a further global influence on nurse education is the curriculum. While Indian curricula are explicitly intended to serve global needs, this does not mean that they are designed to facilitate international migration of nurses. Nursing in India (as part of its professional project) is trying to meet international standards - that such curricula facilitate migration is an unintended consequence:

The Indian nursing curricula is designed to meet the demands of globalisation. It has to meet global healthcare needs especially in the context of developing medical tourism sector. We try to look at the western developments and adopt them as most technological developments happen there. [The] INC syllabus is very much up-todate with any of the countries in the world. (Deputy Director of Nursing Education)

\section{Public-Private Sector Alliances}

In the state sector, nursing was able to pursue its professional project more energetically (in line with analysis of Reverby (1987) where elites and rank-and-file differ in their pursuit of the professional project):

The government says that all students have to do the B.Sc. (i.e. a higher level of qualification) from this year .... Some parts of the profession are keen to be positively enhancing their reputation. (Nurse Educator, State Sector) 
At the same time, it was still subject to the effects of globalisation. As the most prestigious Nursing Colleges are in the state sector, with high entry requirements, their graduates were sought after in the global nursing labour market:

Post-graduation, most of our BSc students are recruited to foreign [countries] (Nurse Educator, State Sector)

The Kerala Government Nurses Association (KGNA) did come out in support of the striking nurses; the first time that public sector nurses supported the strikes. In addition, the strikes were supported by nurse educators in the public sector, suggesting that both public and private sector nurses were making common cause in the pursuit of a nursing professional project. Private nursing schools did not appear to be so committed to the professional project of nursing. As commercial entities, they were more concerned to service the global labour market for nurses, and to provide a workforce for their associated private hospitals. Nurses in the public sector have hitherto been more active in the pursuit of the professional project of nursing in Kerala. This is due to the public sector being more closely regulated by the state, allowing nursing as a profession to influence regulation, and also because public sector nursing is much more heavily unionised

\section{Discussion}

At the most explicitly global level, the strikes can be seen as a consequence of the wider global economic crisis. All the economies of the global North, and the Gulf, experienced a fall in the demand for health care professionals. In addition, visa regulations for migrants to these economies were generally made more restrictive, as states sought to protect the employment of local health care professionals (Kodoth and Kuriakose Jacob 2013). This meant that prospects for migration for Malayali nurses were reduced, with many nurses returning to Kerala having been made redundant from posts elsewhere in the world. An additional intersectionality is at work here where the traditionally gendered division of labour in nursing has changed because of the entry of more men into the profession, who took a leading role in many of the strikes.

The influx of men challenged the traditional gendered division of labour between medicine and nursing (also a site of struggle), resulting in many private hospitals becoming unwilling to employ male nurses. Graduates of the less-prestigious private institutions are at a further disadvantage in the global labour market, due to the lower status of their qualifications. 
These factors had the effect of strengthening the position of the private hospital employers, enabling them to push wages and working conditions downwards, despite the provisions of the State of Kerala Minimum Wages Act of 2009. Nurses had been prepared to accept these wages and conditions, such that they did not protest, when the possibility of a more lucrative career abroad seemed achievable. The global downturn meant that this now looked much less likely; hence nurses became more militant.

\section{Contribution of the Private Sector to the Professional Project}

Although the strikes discussed in this paper started for 'conventional' reasons, they have led to a contribution by private sector nurses to the wider professional project of nursing in Kerala. As the action spread, the demands widened to include, for instance, abolition of the bond system, which constrains the careers of most nurses in Kerala. Certain aspects of globalisation are potentially negative for the pursuit of the professional project in this context. Nurses who see their futures as lying abroad will presumably not be greatly concerned about the status of nursing in their home country and will thus not be so energetic in pursuing activity which supports this professional project. However, this may not necessarily be the case if any diminution of their professional status affects their employment prospects abroad.

\section{Sensitivity of Professional Project to Global Migration Patterns}

Paradoxically, the prospect of migration and the higher earnings that come with it, may simultaneously have benefits for the professional project of nursing in Kerala. Almost all nurses interviewed who intended seeking overseas employment envisaged migration as a short term option to satisfy career objectives - increased knowledge, skills and economic rewards - that could result in long-term professional and social status gains in India. For others, migration was not part of their career plan, yet the increases in status that migration possibilities had brought, were crucial to framing nursing as a 'suitable job' for a growing number of entrants (Johnson 2011). Payment is a good measure of status and the nurses who we interviewed reported that their capacity to earn well and migrate has enhanced their status. Further evidence of this comes from the nurses studied by George (2005) who were in the unusual position (for female migrants), of being the principal earner within their families. This was most clearly shown by a group of interviewees with whom we discussed the marriage prospects of nurses, which they felt were enhanced by nurses' ability to earn money abroad. 
Globalisation had made nursing a more attractive career to men in Kerala. One of the consequences of the global economic downturn was fewer opportunities to work abroad, with the effect that nurses, often led by men, became more militant in pursuing their professional project in Kerala. Thus, globalisation and gender interact - with consequences for professionalisation.

\section{Professional Boundary Issues in an Unregulated Healthcare and Education Market}

Nursing in Kerala is attempting to pursue a professional project analogous to that undertaken by the profession in other parts of the world. The profession has sought to raise the educational standards for entry, enhance the status of education, and improve the working conditions and status of its members, all of which are in line with Larson (1977). In the Indian context, the comparatively low status of nursing as a profession makes the pursuit of this project even harder than it is for nursing elsewhere (Johnson 2011). However, the professional boundary issues considered by, for instance, Svensson (1996) or Allen (1997), where boundaries between nursing and medicine become sites of conflict, or have to be renegotiated, do manifest themselves in the Kerala context, in a more proxy form. This is because many of the owners of private hospitals are doctors. Hence a struggle between employees and employers about wages or working conditions is also, in effect, a struggle between professions of the type analysed by Abbott (1988). Medicine perceives the professional project of nursing as a threat, and as doctors in Kerala, are, in many cases, the employers of nurses, they do not need to employ the tactics used physicians in wealthier countries, working through state regulatory agencies or state health care systems to control nursing's status or scope of professional practice (though this does occur, as we saw above). Instead, they can control the status and work of nursing much more directly. Ironically, one of the main justifications used by employers for measures such as the bond system or 'internships' is the alleged low levels of competence of newly-qualified nurses; an indictment, surely, of the education provided by their own hospitals.

While all professions now operate in a globalised context, nursing in Kerala is more exposed to the forces of globalisation, as large numbers of Kerala nurses continue to leave to work elsewhere in India and the world. The mushrooming of private colleges of nursing, associated with private hospitals, are a response to this demand. It seems likely that given the worldwide recession, this was at least in part a speculative project, leading to a temporary and localised over-supply of nurses. While the profession of nursing has had some success in its professional project vis-à-vis the Indian state, these factors, and the 
nature of local labour markets have weakened it in its relations with professional competitors, and with employers, who in this context are often the same medical professionals.

\section{Conclusion}

Though the professional project of nursing in Kerala displays similar characteristics and processes to that in other contexts, it has several unusual features. Activism to pursue nurses' claims were highly gendered and shaped by global (rather than national) processes. Activism was often initiated by men due to Kerala's political history and tradition of pursuit of workers' rights; yet men only came into nursing due to the transformation in its status, becoming a career with migration prospects. Global processes and changes (in this case the global economic downturn) can have profound impacts on local professional projects. Boundary disputes were shaped by Kerala's strong private medical sector in which hospital management were simultaneously doctors and employers. Poor working conditions and disputes about professional competence were directly linked to a proliferation of private nursing colleges, opened in response to demand due to increased migration prospects.

Kerala provides an example of professional project that is shaped by strong forces above and beyond the usual state and professional actors, notably the private sector and global migration. It provides an example of how a global professional project is shaped by particular, locally and culturally specific intersectionalities of gender, economics, culture and history.

\section{References}

Abbott, A. (1988) The System of Professions. Chicago: Chicago University Press

Abraham M. (1996) Religion, caste and gender: Missionaries and nursing history in south India, Madras, B.I. Publications Pvt Ltd.

Adhikari, R. (2013) Empowered wives and frustrated husbands: nursing, gender and migrant Nepali in the UK, Journal of International Migration 51(6), 168-179

Allen D. (1997) The nursing-medical boundary: a negotiated order? Sociology of Health and Illness. 19, 4, 498-520 
Bhaumik, B. (2013) Can India end the corruption in nurses' training? British Medical Journal. 347:f6881

Biju, B. (2013) Angels Are Turning Red: Nurses' Strikes in Kerala. Economic \& Political Weekly 68(52)25-8

Brush, B. ( 2010) The potent lever of toil: nursing development and exportation in the postcolonial Philippines. American Journal of Public Health. 100(9)1572-81

Chaudhuri P. (2007) Experiences of sexual harassment of women health workers in four hospitals in Kolkata, India. Reproductive Health Matters; 15(30):221-229

Connell, J. (2010) Migration and the globalisation of health care: the health worker exodus? Edward Elgar, Cheltenham, UK and Northampton, MA, USA,

Davies, C. (1995) Gender and the Professional Predicament in Nursing. Buckingham: Open University Press

Dingwall, R. (1999) Professions and social order in a global society. International Review of Sociology $9(1) 131-140$

Etzioni, A. (1969) The Semi-Professions and Their Organization. New York: Free Press.

George, S. (2000) 'Dirty nurses' and 'men who play': gender and class in transnational migration. in Burawoy, M. Blum, J. George, S. Gille, Z. Thaye, M. (eds.) Global Ethnography: Forces, Connections, and Imaginations in a Postmodern World. Berkeley; University of California Press (p144-174)

George, S. (2005) When women come first. Gender and Class in Transnational Migration. Berkeley, University of California Press.

George, S. (2015) 'Real nursing work' versus 'charting and sweet talking': the challenges of incorporation in US urban healthcare settings for Indian immigrant nurses. In Parry, B, 
Greenhough, B. Brown, T and Dyck, I. Bodies Across Borders; The Global Circulation of Body Parts, Medical Tourists and Professionals. London; Ashgate; (p133-153)

Hochschild, A. R. (2000) "Global Care Chains and Emotional Surplus Value" in Hutton, W. and Giddens, A. (eds) On The Edge: Living with Global Capitalism, London: Jonathan Cape

Indian Express (2012) "Post-Mumbai suicide, nurses fight for fair wages"

http://indianexpress.com/article/news-archive/web/postmumbai-suicide-nurses-fight-for-fairwages/

Iredale, R. (2005) Gender, immigration policies and accreditation: valuing the skills of professional women migrants. Geoforum 36 155-166

Johnson, S. (2011) A suitable role: professional identity and nursing in India. PhD thesis, London School of Hygiene and Tropical Medicine.

Kingma, M. (2006) Nurses on the Move: Migration and the Global Health Care Economy. New York, Cornell University Press.

Kodoth, P. and Kuriakose Jacob, T. (2013) International Mobility of Nurses from Kerala to the EU: Prospects and Challenges. San Domenico di Fiesole: European University Institute

Lorenzo, F., Galvez-Tan, J., Icamina, K \& Javier, L. (2007) Nurse migration from a source country perspective; Philippine country case study. HSR Health Services Research 42(3) 1406-1418

Masselink, L. \& Lee, S. (2010) Nurses, Inc.: expansion and commercialization of nursing education in the Philippines. Social Science \& Medicine 71(1):166-72

Nair, S. (2010) Nurses' Strikes in Delhi: A Status Question. Economic and Political Weekly Vol. 45 , No. 14 pp. $23-25$

Nair, S. (2012) Moving with the times: gender, status and migration of nurses in India. New Delhi, Routledge, 
Nair, S. and Percot, M. (2007) Transcending boundaries: Indian nurses in internal and international migration. Centre for Women's Development Studies Occasional paper. CWDS: New Delhi

Nair, S. Evans, C., and Timmons, S. (2016) Nurses in the Private Health Sector in Kerala. Any Lessons Learned From Their Recent Strikes? Indian Journal of Gender Studies 23(1) 825

Ortiga, Y. (2014) Professional problems: The burden of producing the 'global' Filipino nurse, Social Science and Medicine 115, 64-78

Percot, M. (2006) Indian nurses in the Gulf: two generations of female migration. South Asia Research 26(1) 41-62

Percot, M and Irudaya Rajan, S (2007) Female emigration from India. Economic and Political Weekly 42(4)318-25

Prescott, M., Nichter, M. (2014) Transnational nurse migration: future directions for medical anthropological research, Social Science \& Medicine, 107, 113-123

Rankin, J. (2009) The Nurse Project: an analysis for nurses to take back our work. Nursing Inquiry. 16: 275-286

Reverby, S. (1987a) Ordered To Care: The Dilemma of American Nursing (New York: Cambridge University Press

Reverby S. (1987b) A caring dilemma: womanhood and nursing in historical perspective. Nursing Research. 36(1):5-11.

Robertson, R. (1992) Globalization: Social Theory and Global Culture. London: Sage. Larson MF. (1977) The Rise of Professionalism: A Sociological Analysis. Burbank: University of California Press.

Ronquillo, C., Boschma, G., Wong, S. and Quiney, L. (2011) Beyond greener pastures; exploring contexts surrounding Filipino nurse migration into Canada through oral history. Nursing Inquiry 18 (3) 262-275 
Somjee G. (1991) Social change in the nursing profession in India, In: Holdon P \& Littlewood $\mathrm{J}$ (eds), Anthropology and Nursing, London, Routledge, p.31-55

Svensson R. (1996) The interplay between doctors and nurses - a negotiated order perspective. Sociology of Health \& IIIness. 18, 3, 379-398.

Thomas, P. (2008) Indian nurses seeking new shores (p 99-110) In Connell, J. (ed.) the international migration of health care workers. London: Routledge

Walton-Roberts, M. (2010) Student nurses and their migration plans; A Kerala case study. India Migration Report 2010 Routledge; New Delhi

Walton-Roberts, M. (2012) Contextualizing the global nursing care chain: international migration and the status of nursing in Kerala, India. Global Networks 12, 2175-194

Walton-Roberts, M. (2015) International migration of health professionals and the marketization and privatization of health education in India: From push-pull to global political economy. Social Science and Medicine 124; 374-382

Walton-Roberts, M and Rajan, I.S. (2013) Nurse emigration from Kerala: 'Brain circulation' or 'trap'? India Migration Report 2013. Routledge: New Delhi.

Witz, A. (1992) Professions and patriarchy. London: Routledge.

Yeates, N. (2009) Production for export: the role of the state in the development and operation of global care chains. Population, Space and Place 15; 175-187 